\title{
Research on Discrete Dynamic System Modeling of Vocal Performance Teaching Platform Based on Big Data Environment
}

\author{
Xiaohui Gong (iD) \\ School of Music and Dance, Yantai University, Yantai, Shandong 264003, China \\ Correspondence should be addressed to Xiaohui Gong; gongxiaohui@ytu.edu.cn
}

Received 2 November 2021; Revised 30 November 2021; Accepted 5 January 2022; Published 24 February 2022

Academic Editor: Gengxin Sun

Copyright (c) 2022 Xiaohui Gong. This is an open access article distributed under the Creative Commons Attribution License, which permits unrestricted use, distribution, and reproduction in any medium, provided the original work is properly cited.

\begin{abstract}
The traditional teaching model of national vocal music in colleges and universities has some problems, such as low quality of teaching, poor diversity of teaching, and low interest of students. Based on this, this study studies the innovation of the teaching model of national vocal music in colleges and universities based on the deep recurrent neural network algorithm and designs the teaching quality evaluation model based on the deep recurrent neural network algorithm. The collection of data and information is realized from the aspects of students' class state, vocal music examination results, classroom interaction, etc., and the comprehensive analysis is carried out using the deep recursive neural network algorithm, to realize the multiple analysis and objective evaluation of the whole process of different teaching modes of national vocal music in music colleges and universities, according to the different characteristics and teaching objectives of the teaching process of national vocal music in music colleges and universities The standard requires accurate analysis and evaluation. The results show that the optimization model based on the deep recurrent neural network algorithm has the advantages of high feasibility, high intelligence, and wide range of applications. The experiments show that the deep recurrent neural network algorithm can analyze the effectiveness of the innovation model, and the fuzzy evaluation method can realize the comprehensive evaluation of the innovation mode, which is conducive to the improvement of students' vocal music learning ability.
\end{abstract}

\section{Introduction}

The development of computer technology and network technology is profoundly changing people's work, study, and living habits, especially their unique advantages in information storage, retrieval, dissemination, etc., and they have become an indispensable tool for modern people. Similarly, with the development of computer technology and the continuous progress of network technology, educational technology. Especially in recent years, with the emergence of network teaching and distance education, the rapid development and popularization of network [1].

At present, under the background of modern education theory and teaching practice experience, we can make full use of modern teaching methods to optimize classroom teaching and make traditional teachers to promote quality education and ability education, promote educational transformation, and improve educational efficiency [2]. The student-centered teaching mode has been transformed into a new teaching mode dominated by students and teachers, which has become an important teaching mode. Schools need to strengthen students' ability of autonomous learning, interactive learning, and collaborative learning and improve students' ability of autonomous learning, discovering, and exploring knowledge.. The current education sector is an important issue to be solved urgently [3].

After nearly a decade of development, at present, the vast majority of colleges and universities have consciously applied modern education technology to teaching, and the vast majority of students already have the use of computer and network basic skills and the use of computer technology and network technology to assist teaching, not only to improve students' skills in computer and network technology, but also to improve students' interest in learning, to stimulate students' self-learning consciousness and explore the spirit, so as to improve students' knowledge and control of knowledge, to 
achieve the purpose of granting people to fishing [4]. Vocal music education is different from the teaching of other music disciplines. It adopts a relatively abstract way of education. In addition to external performance, intuition is poor. This method often relies on experience and feelings to teach skills and skills. For example, there is a certain degree of difficulty in learning. The traditional vocal classroom teaching continuity is poor; Students can only practice with temporary memory in class. If the voice of the class recorded down, which can make the classroom teaching has been extended, students can accord their own good voice in the classroom to guide the practice to their own as a reference, and the classroom will feel a longer time to save and to consolidate to accurately master the processing of the music. In addition, the traditional vocal music teaching is mainly through the live piano accompaniment way, but now can also be implemented through digital teaching methods. Digital vocal music teaching can be preaccompaniment for the song, emphasizing the style and rhythm, so that students establish a good rhythm ideas and style concepts, to achieve the accuracy of expression and improve the ability to express the song. Moreover, digital music teaching mode can also introduce diversified music education into vocal music classroom. This enables students to accept the cultivation of multiple singing abilities while learning singing. In addition, students can record the process of timely recording and playback, and training students' singing and stage performance. In recent years, with the expansion of college enrollment, the number of students is increasing, but the vocal music teachers with a certain teaching level are relatively limited. With the introduction of digital teaching, more students can get equal and high-quality vocal music education opportunities in a certain period of time. Such as the processing of vocal music works, singing demonstration, language expression and other skills, which greatly shortens the teaching time [5]. Finally, the use of digital vocal teaching methods to provide students with more to see, listen, and practice more conditions and platform for vocal music teaching has brought a new situation.

This study studies the innovation of college national vocal music teaching model based on deep recurrent neural network algorithm and designs a teaching quality evaluation model based on deep recurrent neural network algorithm. The innovative arguments of this study are as follows: (1) the hierarchical structure and index relationship of the whole national vocal music teaching innovation system are clarified. (2) The innovative teaching model is evaluated from multiple angles, which provides an all-round index sample for the establishment of intelligent vocal music teaching quality evaluation system in colleges and universities. (3) Through the application of digital teaching module of vocal music teaching website, students' skills and master skills are improved, and students' learning efficiency is significantly improved.

This study is divided into five parts. The first part expounds on the background of the current research. The traditional teaching model of national vocal music in colleges and universities has some problems, such as low teaching quality, poor teaching diversity, and low students' interest in learning. This study studies the innovation of college national vocal music teaching model based on deep recurrent neural network algorithm and puts forward a teaching quality evaluation model based on deep recurrent neural network algorithm. The second part cites the relevant literature. The third part describes the system design and implementation, including the discrete and dynamic construction of vocal performance teaching platform, the implementation process and steps of teaching model quality evaluation model, and the design and implementation of subsystem. Finally, the full text is summarized. The experiments show that the deep recursive neural network algorithm can analyze the effectiveness of the innovation mode, and the fuzzy evaluation method can realize the comprehensive evaluation of the innovation mode, which is conducive to the improvement of students' vocal music learning ability.

\section{Related Work}

The function of vocal music teaching website requires website developers and website users to communicate, coordinate and communicate. Determine the functional modules of the website, and then provide the basis for the design, implementation and use of the website. According to different user entities, the system can be divided into modules such as login module, personnel management module, course content management module, and online learning module [6]. For different users, vocal music teaching website has different functions. For vocal music teaching management personnel (including educational administrators and faculty leaders, and teaching and research director), you can use the website to achieve the vocal network teaching information editing, collection, summary, statistics, and monitoring vocal network teaching, while managing student learning and instructing the teacher to teach. For vocal music teacher users, you can use the vocal music teaching website and update the teaching content and the student's online teaching and guidance [7]. For student users, you can use the vocal music teaching website for online learning, including the search song and works of music terms and song work analysis and introduction; by listening and comparing the different singers' singing, to deal with works is learned [8]. These vocal online teaching function classes have a good amount of information multiplied effect. For anonymous users, vocal music teaching website is a platform for the dissemination of knowledge, skills, and culture; for the popular vocal culture, the quality of music is improved and music has a certain role in promoting. In addition, vocal music teaching site also cites search function and notification notice function. Users can use the in-site search function to search for relevant or interesting content [9]. To facilitate students or teachers to keep abreast of the latest developments in the school, a variety of performance registration, training courses, examination arrangements, curriculum adjustments, large events, and evening and other information can be placed in the dynamic notice of the notice to facilitate students and teachers in a timely manner [10]. 
Through investigation, the users of vocal music teaching website mainly include the following: personnel department, educational administration department, teachers, students, and anonymous users. The users of the personnel department can edit the information of each course teacher through the website, including the promotion of teacher's title, the adjustment of teaching units, and the management of rewards and punishments.

2.1. System Requirement Analysis. Think PHP framework is a free open-source framework, using object-oriented development structure and model view controller (MVC) model. In the traditional Web mode, the functions of page display and data processing are usually coupled in the page code, which makes the system coupling degree not conducive to the expansion and maintenance [11]. The MVC model divides the program into three parts: the model, the view, and the controller, reducing system coupling and improving system performance. A framework of the application greatly improved the distance learning system development efficiency, scalability, and maintainability, reducing the difficulty of development and maintenance [12]. Therefore, on the basis of the experience of many vocal teachers in network teaching, the author has carried on the beneficial exploration and the practice to the integration of the information technology, the digital music software, and the network teaching and has put the result into the vocal music teaching website. In the design and development, ThinkPHP is used as the website and website management development tool, so as to complete the design and production of vocal music teaching website [13]. The establishment of this site for the traditional vocal music opened up a new path. Online education is shown in Figure 1.

The users of the educational affairs department are mainly the vice president (deputy director) and the teaching secretary of the school education office and the department in charge of teaching [14]. On the one hand is the curriculum arrangement of teachers, on the other hand is the management of students, including the allocation of students to a class. Classes are divided into majors, student majors, class adjustment, curriculum arrangement, student achievement review, statistics, summary and printing. Teachers on the one hand can update the maintenance of teaching content, and on the other hand, students can submit online work, test papers for review, performance log, report, etc., can also communicate with students online to answer questions raised by students, and learn to give advice and so on as shown as follows:

$$
I(x, y)=L(x, y) \times R(x, y) .
$$

Student users are the main users of vocal music teaching website, the main service object of the website [15]. Student users can learn a variety of music-related knowledge through the site; you can complete online homework, online examination, online questions, and exchange. Anonymous users can only browse the contents of the site, on-demand music, and video, cannot ask questions, Q\&A, and modify the teaching content, as the vocal music teaching website is a comprehensive teaching site. Therefore, the website is closely related to the specific institutional and professional settings of the school. There are several majors, and each major is composed of different curriculum modules. These modules need to be analyzed, designed, and implemented. The users of the system include educational administrators, webmasters, teachers, and student users. Through the above analysis, the main function of the website is to provide students with rich teaching resources, so students' functions are the most abundant. The analysis of the above roles is summarized, and the functional block diagram of the system can be obtained. The system is divided into three types of users: students, teachers, and administrators, and the needs of different users are as follows:

(1) Students

(1) To understand the syllabus, teaching objectives, learning points, priorities, and difficulties

(2) Independent learning teaching courseware and teaching video, access to the course of relevant learning materials

(3) Independent online test learning effect, and after-school review and remote experiment

(4) Students can communicate with the course host teacher remote interaction and learning Q\&A

(5) The use of Internet resources and technology to enhance the function of the system and expansion

(2) Teachers

(1) Check the student's registration information, learning progress, test results, and experimental situation

(2) Update the syllabus, teaching objectives, learning points, priorities, and difficulties

(3) Update the teaching courseware, teaching video, and curriculum-related information to meet the needs of students to self-study

(4) To interact with students and forum Q\&A

(3) The administrator

(1) Add and delete user and management user registration information

(2) View the information in the study forum, sort the information, and timely clean up expired posts

(3) Manage teaching courseware, teaching video, and related learning materials

(4) Manage learning records and experimental information

(5) Update the news bulletin

2.2. Mobile Learning Method. Mobile learning brings many changes to the education industry: greatly enhanced the purpose of oriented learning, brought the form of debris learning, and reflected the teaching of the center of the 


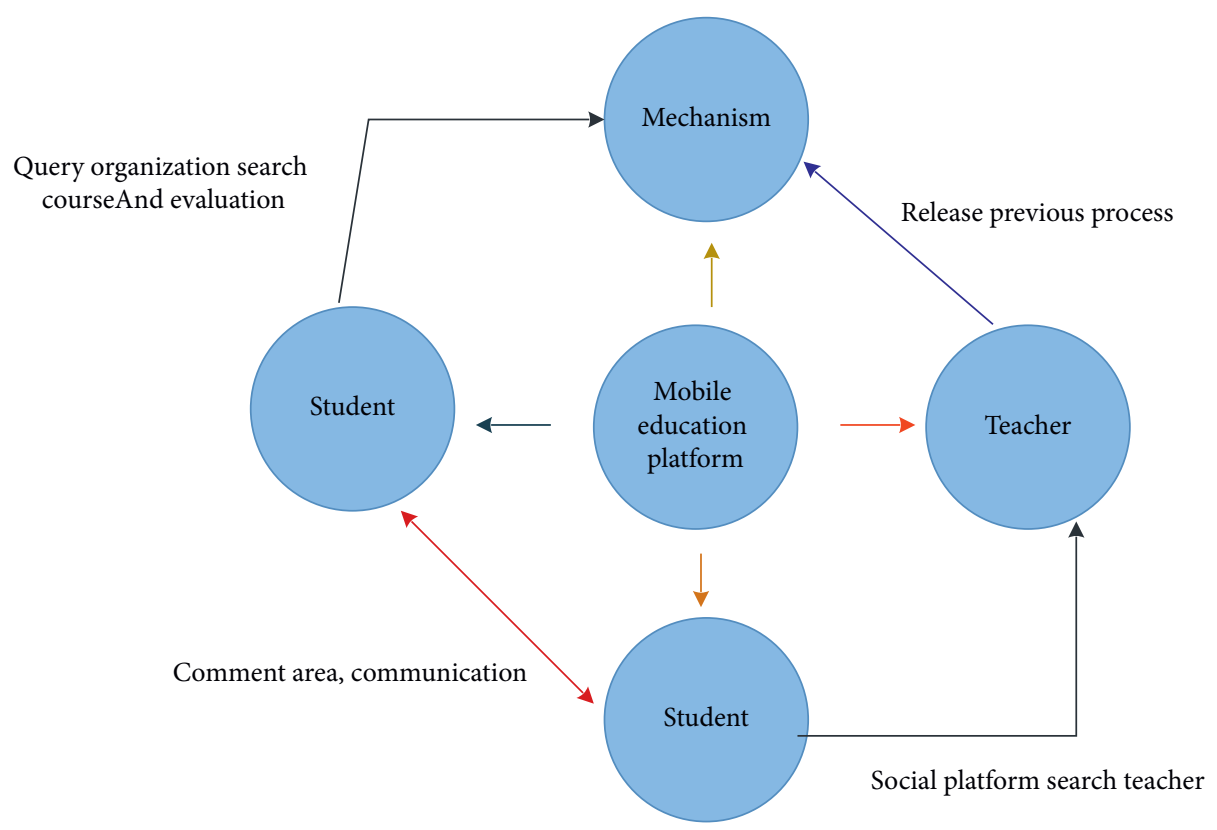

Figure 1: Online education platform.

learners. Mobile learning is a combination of mobile Internet and modern education, the product of continuous development. With the expansion of distance education and E-teaching, mobile learning emphasizes the subjectivity of learners. For example, in the process of daily work and study, if you encounter any ambiguous problems, you can immediately use your mobile phone to search keywords. Many reference answers and related information will appear on the network. Now is an era of information explosion, the face of mass information content, most people cannot take the initiative and systematic learning knowledge, only when used to check this study, and mobile learning is to meet people's needs as shown as follows:

$$
\lg [R(x, y)]=\lg [I(x, y)]-\lg [L(x, y)] .
$$

Debris time refers to the time of day-to-day work, such as in the rest of the class, the station, and other vehicles, when the car and the supermarket checkout queuing and so on [12]. In the mobile learning method before the emergence of these, debris time is wasted in vain, and now, people can mobile devices and other mobile devices anytime and anywhere to learn. With the rapid development of mobile Internet, how to use these scattered time has attracted more and more attention. The research on the use of fragmented time has even given birth to many mainstream mobile applications. People use mobile devices to learn a knowledge point. These knowledge points are interrelated, and finally form a complete knowledge system. People can find their own content in the vast ocean of knowledge at any time and anywhere, using mobile devices to connect to the Internet, and then connect them to form their own complete knowledge system, which is scattered learning.

In the rapid development of mobile Internet today, all this becomes possible. Mobile learning has also changed the way of classroom teaching. The remarkable feature of mobility is that mobile Internet makes more efficient use of fragmented time for learning activities, which has become the top priority of mobile teaching. Mobile Internet is easier than the traditional Internet to fundamentally change people's lives. From mobile phone games to social chat dating, a variety of mobile applications are constantly close to the distance between people. Originally the so-called multimedia teaching, but the content from the blackboard to the projector, information from teachers to students oneway communication. Students acquire knowledge passively and have no initiative in learning. Long-term learning will inevitably lead to the reduction of learning interest. If students adopt a mobile learning approach, they find the content from the Internet, from the screening, and then access to knowledge of the way to be more interactive and target, that is, the purpose of the abovementioned purposeoriented learning, that is, school that is used. For example, students cannot do the exercises; you can scan by the twodimensional code next to the network, then find the answer and explain, and can also initiate or participate in the discussion. However, although the computer is widely used, it is contrary to the definition of mobile learning. The equipment used in the mobile learning process must be able to effectively provide an interactive way between teachers and students and effectively display the learning content shown as follows:

$$
L(x, y)=F(x, y) * I(x, y) .
$$

The students focus on learning different things and teachers cannot meet all the learning needs, which are the drawbacks of traditional teaching, but the mobile learning is different; you can break down the contents of a lesson into a small knowledge point, which is mentioned above, the knowledge of debris. All students according to their own confusion and doubt see their own knowledge of debris, 
when the combination of these fragments in series forms a complete knowledge system. The whole process is guided by students' self needs, which can be more effective and interesting. When mobile learning is introduced into classroom teaching, information will become cross and parallel, breaking many original restrictions. Compared with traditional multimedia teaching, mobile learning is like everyone can customize a learning system according to the needs of students. This is consistent with the requirements of the current curriculum reform and is in full compliance with the direction of development of teaching reform. The user login screen is shown in Figure 2.

\section{System Design and Implementation}

Entity relation diagram, which is a necessary process for modeling final databases, is a tool that represents the consistency of data requirements and is independent of the type of database used. Regardless of what type of database the project is built on, the conceptual data model remains the same, which is what is known as the "freedom of realization" of the model. Students enter the account number and password in the login interface, select the user to submit the form, and match the information in the database to enter the front desk learning subsystem home page, otherwise, give the wrong message.

Even without using the database, the data model remains the same, just as the data are eventually written on a few sheets of paper or put into a filing cabinet. The network teaching can use multimedia technology, sound, images, video, and other information to show students, and traditional teaching methods complement each other. You can use music basics and music in the form of Web pages in the terminal computer preview and help students' self-study. The teaching content will be presented to students in the form of music, dance, video, vocal music and other images. It is intuitive and vivid, which can significantly improve the effect of music teaching.

\subsection{Discrete Dynamic Construction of Vocal Performance} Teaching Platform. At present, genetic algorithm, particle swarm greedy algorithm, and neural network algorithm are the most successful intelligent models in the research of optimization and teaching quality evaluation. The neural network algorithm is an algorithm (as shown in Figure 2) based on the inspiration of traditional biology in the process of neural network. In essence, it is a direct, global random search method that does not depend on specific problems. As a practical, efficient, and robust optimization technology, the deep recurrent neural network algorithm develops rapidly and has been widely used in various fields (pattern recognition, neural network, image processing, machine learning, industrial optimization control, adaptive control, biological science, social science, etc.); for example, the algorithm framework based on neural network and PMANE in industrial production is shown in Figure 3 [16].

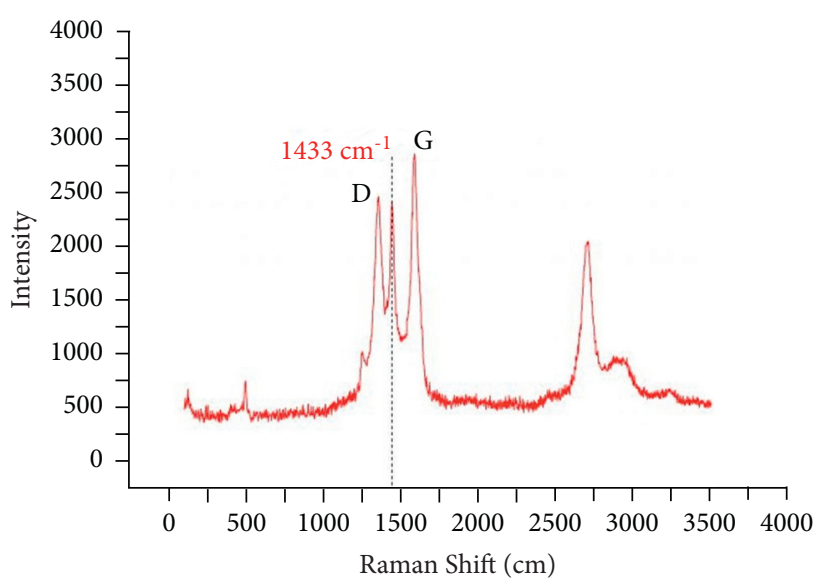

Figure 2: Raman shift.

Based on the innovative evaluation model, this paper studies and puts forward the application of national vocal music teaching model in music colleges and universities. Based on the deep recurrent neural network algorithm, the deep recurrent neural network algorithm based on the influence degree of multidimensional index factors is designed first, that is, according to the level differences in the national vocal music in different levels and different teachers in the music colleges and universities, and the same teacher has different teaching qualities. In terms of the differences in teaching quality of vocal music teaching content, the highly targeted deep recurrent neural network algorithm is used to realize the global random search for detailed teaching quality evaluation of different teaching modules and carry out differentiated teaching. Then, through the deep recursive neural network algorithm in the teaching of national vocal music in colleges and universities, a series of information in the teaching process is accurately divided, to achieve the high classification of different qualities of teaching model in the teaching process of national vocal music in colleges and universities and produce the goal of highly collaborative correlation (the teaching model of national vocal music in colleges and universities is divided into boundary) to the next stage of the process to be optimized, to achieve a special goal-oriented high-quality teaching and accurately improve the stability of vocal teaching innovation mode.

3.2. Realization Steps of Innovative Teaching Model of National Vocal Music. In this link, in the process of constructing the optimization model and evaluation link of national vocal music teaching based on the deep recurrent neural network algorithm, we will classify the students in different stages according to the similarity of vocal music teaching model and the collaborative similarity of students' learning ability of vocal music course and then classify the teachers in the national vocal music teaching of music colleges and universities. To ensure the stratification and renewal of the student groups in the teaching process of the national vocal music teachers in the music colleges and universities, the second division of the performance data information in the process is carried out, and the second 


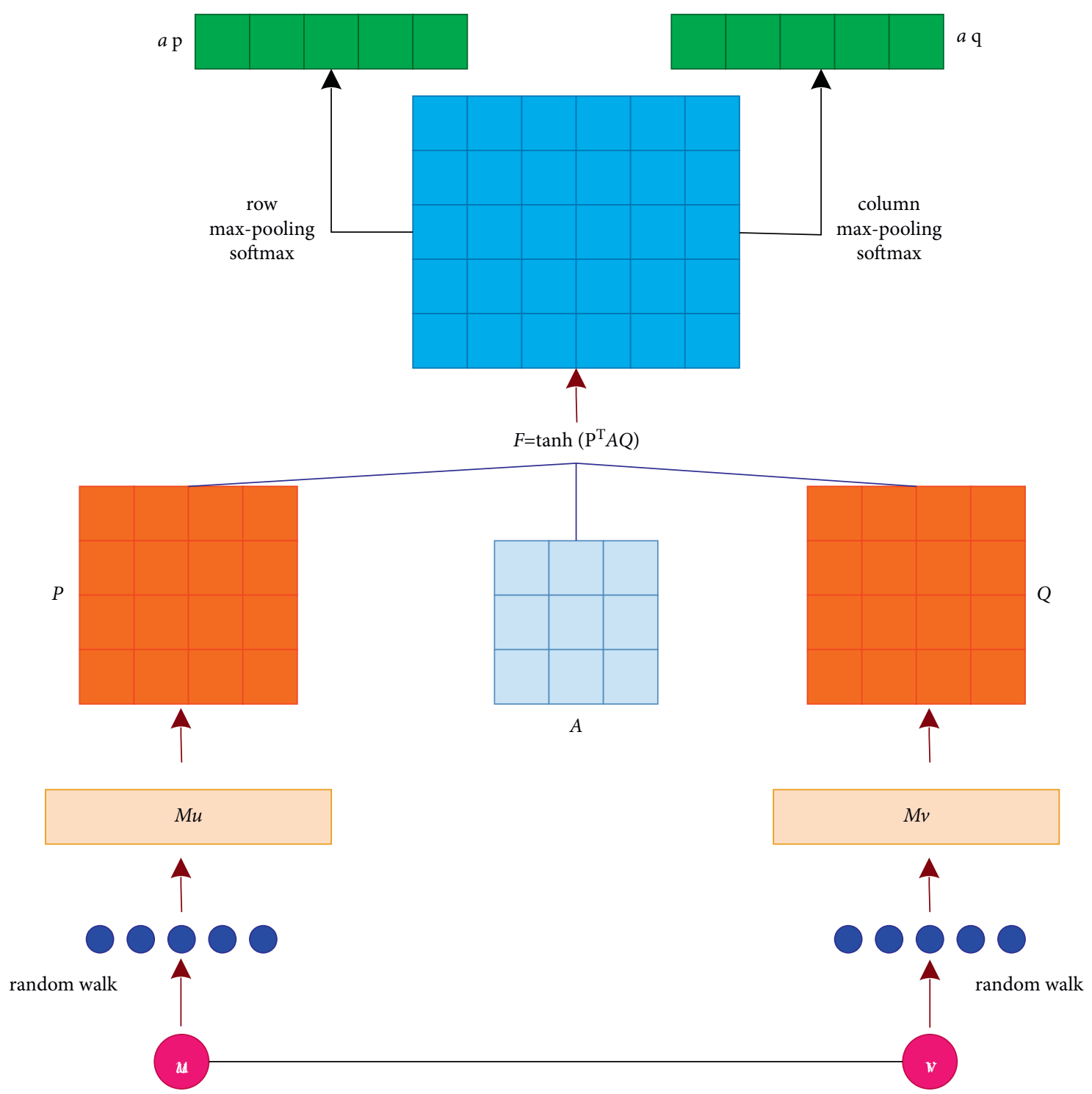

FIgURE 3: Algorithm framework based on neural network and PMANE.

division and renewal of the nearly divided student groups are realized through the deep recursive neural network algorithm selection. The steps are as follows:

The first step is to select the neural network coding strategy and transform the parameter set (feasible solution set) into the neuron structure space of the deep recurrent neural network algorithm. To realize this process, we combine a new evaluation method of teaching quality of national vocal music based on multi-factor coupling model, use the coupling sequence after deformation to randomly disorder the common teaching methods of national vocal music, and then decouple them to realize the optimal determination of different students' vocal music teaching methods. Finally, we carry out simulation verification and find that the national vocal music teaching method of this music college is the best. The teaching quality evaluation program has good objective evaluation ability.
Therefore, according to the different teaching model and teaching contents, the national vocal music course in music colleges and universities will form specific vectormatrix groups, which are composed of different vector groups. These vector groups have different vector eigenvalues according to the similarity of students' learning ability to different vocal music courses, thus realizing the storage and processing of spatial vector and digital information based on the teaching ability of vocal music teachers and existing level data in the process of national vocal music teaching in the same music college. In this study, the deep recurrent neural network algorithm used to deal with this similar information is based on the different quality levels of the national vocal music teaching model in different music colleges and universities. It realizes the secondary division of different students in the same music college and the same level of students in the national vocal music teaching in different music colleges and universities. 
In the second step, the node function of neural network is defined to calculate the fitness value of the function. We put a student group sequence $s=(C 1, C 2, \ldots)$, which accords with the algorithm rules $(\mathrm{CN}, \mathrm{CN}+1)$ $(\mathrm{CN}+1$ is $C 1)$ as an individual. The reciprocal of the sum of the distances between the adjacent students in this sequence can be used as the calculation degree of the corresponding individual $s$ neural node, so the node function of the neural network is as follows:

$$
f(s)=\frac{1}{\sum_{i=1}^{n} d\left(c_{i}, c_{i+1}\right)} .
$$

The basic implementation process of this step is as follows: for individuals, $s=(C 1, C 2, \mathrm{CN}, \mathrm{CN}+1)$. However, it is not very easy for such individuals to code [17]. Because if the coding is not correct, the illegal student sequence or invalid solution will appear when the crossover or neuron transfer operation is implemented. For example, for the relevant data characteristics of five students, we use the symbols $a, B, C, D$, and $e$ to represent the corresponding student individual and use the sequences of these five symbols to represent the possible solution, that is, the neuron node center (Thanh Nguyen) in the deep recursive neural network algorithm [15]. The result is shown in Figure 4.

Set up

$$
\begin{aligned}
& s_{1}=(A, C, B, C, B, A), \\
& s_{2}=(A, C, B, C, B, A) .
\end{aligned}
$$

Then, we carry out the conventional recursive or neighborhood operations in the deep recurrent neural network algorithm, such as the postexchange three bits, and get

$$
\begin{aligned}
& s_{1}^{\prime}=(A, C, B, C, B, A), \\
& s_{2}^{\prime}=(A, C, B, C, B, A) .
\end{aligned}
$$

The second $C$ of neuron node $S 1$ is changed to $e$, and

$$
s_{1}^{\prime \prime}=(A, C, B, C, B, A) \text {. }
$$

From this, we can see that $s_{1}^{\prime}, s_{2}^{\prime}$, and $s_{1}^{\prime \prime}$ obtained above are all illegal sequences. To solve this problem, we process the evaluation data of the national vocal music teaching model with $P$ number of students in the same spatial position stage by set operation (recursion, neighborhood regression operation) and pairing regularization of neuron nodes and carry out multiple comparison analysis. When each student object belongs to the central set of the corresponding nearest neuron node, the iterative processing is ended.

We set the size of student group as $X$ and the recursive space of target neural network as $D$ dimension.

$$
X_{i}=\left(W_{i 1}, W_{i 1}, \ldots, W_{i D}\right)^{T},
$$

where $I$ is the $I(I=1,2,3)$.

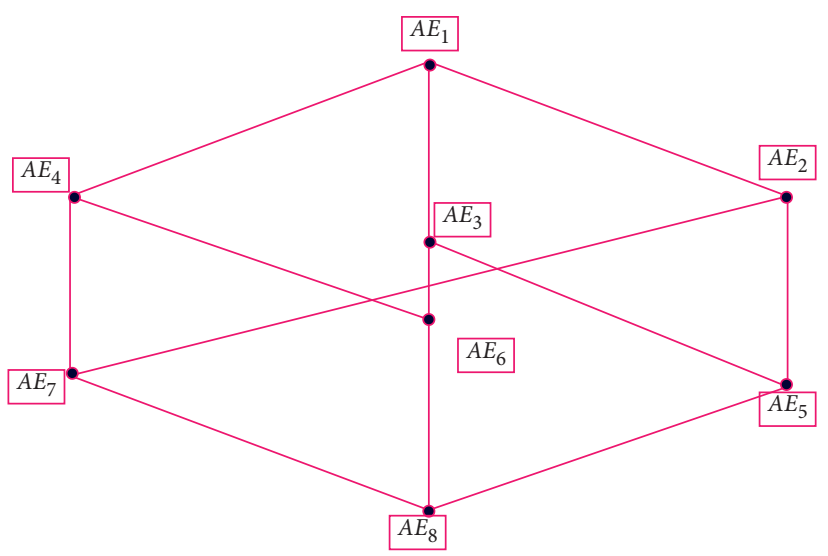

FIgURE 4: Results after deep recursion.

$$
W_{i}=\left(W_{i 1}, W_{i 1}, \ldots, W_{i D}\right)^{T} .
$$

$I(i=1,2,3, \ldots)$ represents the node recursion speed of $I$.

The third step is to restore some data information through the database information of the deep recurrent neural network system and the preset automatic judgment program, so as to realize the reprocessing processing of the secondary data information, and then to form four-node centers [16]. Then, some irrelevant or meaningless data information is purposefully deleted or removed, and recorded by means of vectors, forming special data information records and realizing the transformation of data information into vector information, and in and out of storage. For example, when it is necessary to classify the same kind of data information, it can be compared according to these vectors with special data information recording function. When the coincidence degree meets the preset requirements, it can realize the data processing, judgment, and classification of the target data.

3.3. The Realization Process and Steps of the Quality Evaluation Model of National Vocal Music Teaching Mode. In the quality evaluation model of national vocal music teaching model in music colleges and universities, to enable different students to maximize their vocal music ability level according to their existing vocal music level and feature information status, the depth recurrent neural network algorithm based on variable weight neural network factor is adopted first, and three feature parameters related to vocal music teaching model index are selected. In addition, it puts forward a scheme system of collecting core parameters of vocal music teaching model and evaluating teaching quality based on fuzzy evaluation. Through the research on the common teaching model and students' learning ability of national vocal music in music colleges and universities, this study clearly defines the hierarchical framework and index relationship of the whole teaching model system of national vocal music in music colleges and universities. This study validates the innovative method of this comprehensive 


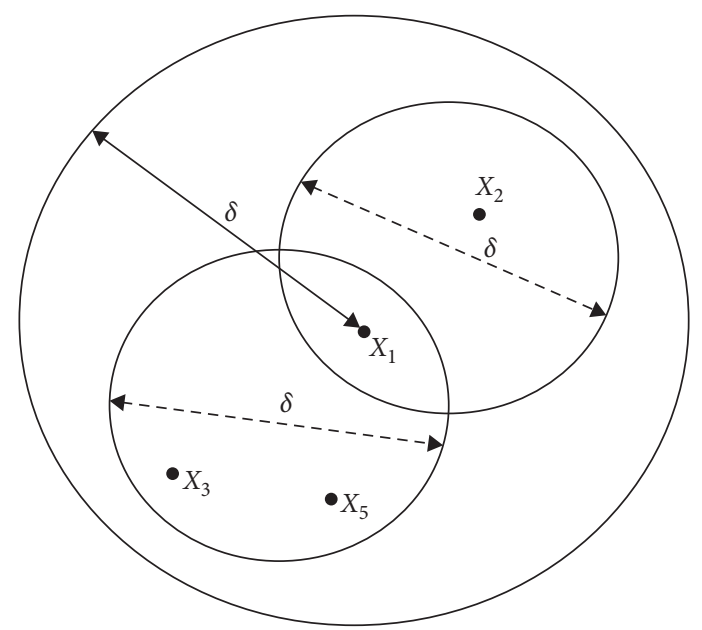

FIGURE 5: Data information processing in multi-pointer mode.

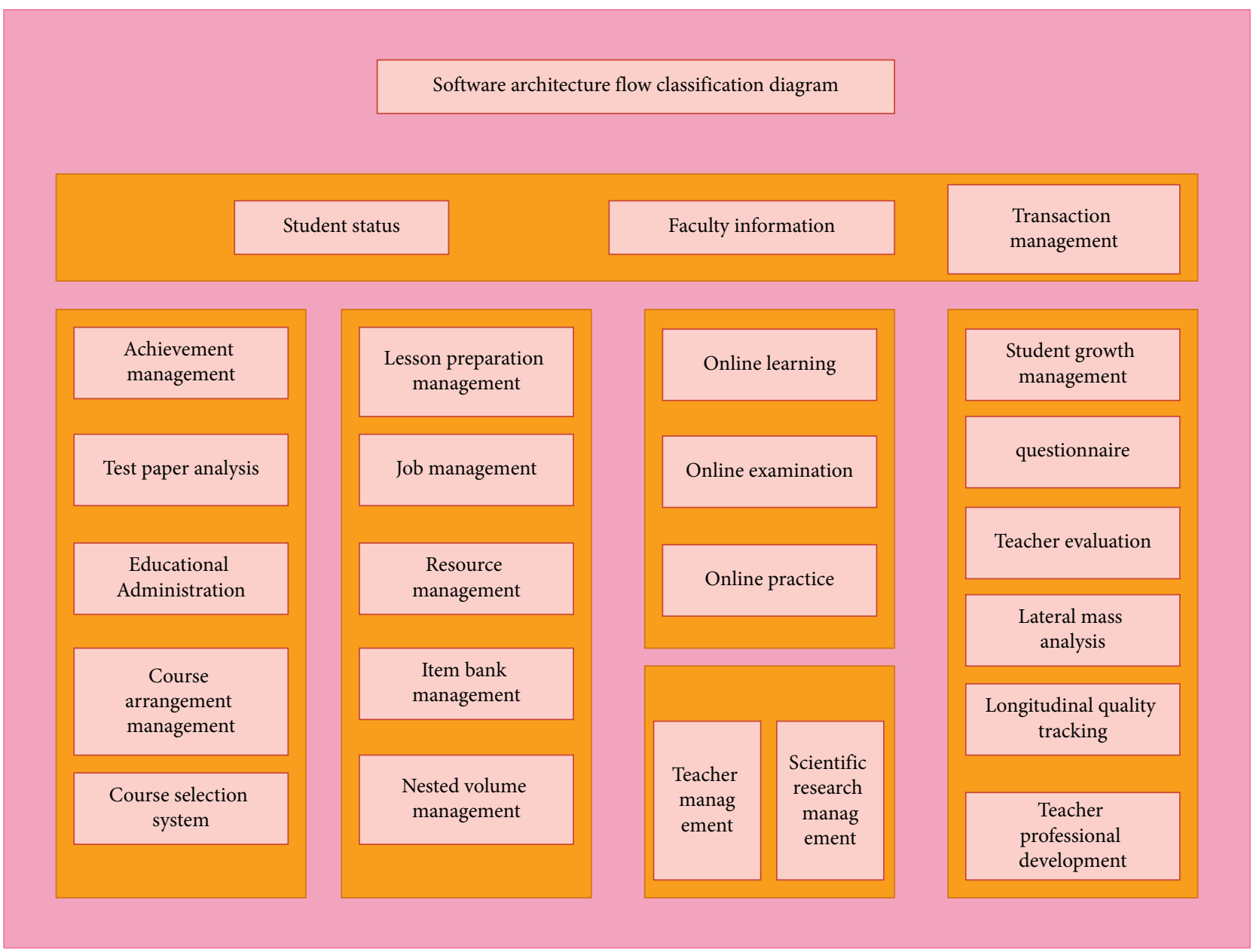

Figure 6: Teaching management system.

model from multiple perspectives, provides a comprehensive index sample for the evaluation of the national vocal music teaching model in the intelligent music colleges and universities, then analyzes the characteristics of the required vocal music teaching data using the deep recursive neural network algorithm, and finally conducts the comprehensive and objective evaluation using the neural network method. The specific implementation process is as follows: 
First, the students of national vocal music in colleges and universities should first reflect the level information, determine the appropriate recursive strategy according to the corresponding eigenvalues and fitness, and realize the random generation of initialization neuron nodes Paiva et al. [14]. When the characteristic values of any two teachers in the group are different, it means that the teaching level of the two teachers is greatly different, and the automatic separation will be realized. The recursive adaptive values in the group will be calculated and compared with the characteristic values and adaptability of the next student. When the deep recursive neural network algorithm is used to mine the teaching quality level of different teachers, it will produce different similarities between the students corresponding to the national vocal music level of music colleges and universities.

Second, in the process of the research on the evaluation model of national vocal music teaching quality in music colleges and universities based on the deep recurrent neural network algorithm, in the actual process of vocal music teaching for a specific group of students, the deep recurrent neural network algorithm transforms the information of national vocal music learning characteristic level of the target group of students into the data that can be recognized by the computer through specific processing data information (such as vector groups and matrices) [13]. In addition, the multipointer mode is adopted to process the teaching data information under the characteristic level of national vocal music in different colleges and universities, as shown in Figure 5.

We assume that $x_{i}=\left(x_{i 1}, x_{i 2}, \ldots, x_{i p}\right), x_{j}=\left(x_{j 1}\right.$, $\left.x_{j 2}, \ldots, x_{j p}\right)$ is the observation value of the listening effect of the $I$ and $j$ students.

3.4. Design and Implementation of Subsystem. In the front desk learning subsystem home page, different links are clicked to enter a different page, the navigation bar in the course of learning is clicked or click the start learning icon to enter the learning page of the login page of the background management subsystem, administrator privileges are selected, the user name and password are entered, and the background is entered. The management subsystem, the left side of the navigation bar, shows that the administrator can operate all the modules. Student management is clicked, the student management interface is entered, and you can view all students in the list of student numbers, names, and classes. You can insert a new student user or change the user information to the database. Due to limited space, teacher user function is no longer introduced here. The system uses the entity contact method to design the database. First of all, according to the actual needs of users, the different entities, attributes, links, and E-R diagram are intuitively identified. After that, the entities, attributes, and associations are transformed into relational models of the relational database by the relevant conversion rules, and the attributes, keywords, and integrity constraints of each relational schema are determined as shown in Figure 6.

\section{Conclusion}

To improve the teaching quality of national vocal music in Chinese music colleges and universities, it is imperative to innovate the model of national vocal music. Based on this, this study uses the deep recurrent neural network algorithm and the fuzzy evaluation model. Firstly, three characteristic parameters related to the teaching quality of national vocal music are selected, and an evaluation system based on the characteristic parameters of the teaching quality of national vocal music is proposed. Through the research on the five aspects of the teaching quality of vocal music classroom listening state, vocal music playing ability, vocal music writing ability, final examination results, and listening satisfaction, this study clearly defines the hierarchical framework and indicator relationship of the whole national vocal music teaching innovation system. Secondly, this study evaluates the innovative teaching model from many angles and provides all-round index samples for the establishment of the intelligent vocal music teaching quality evaluation system in colleges and universities. According to the characteristics of vocal music courses, the best performance methods are chosen, to guide teaching and to maximize the quality of teaching and teaching effectiveness. With the application of digital teaching module of vocal music teaching website, we can deepen students' perceptions of knowledge through video, animation demonstration, online appreciation, online communication, online teaching, and simulation analysis and accelerate students' skills and skills of the master, so that students learn efficiency significantly improved. Finally, the experiment shows that the effectiveness of the innovative mode can be analyzed using the deep recurrent neural network algorithm, and the comprehensive evaluation can be realized using the fuzzy evaluation method, which is conducive to the promotion of students' vocal learning ability. However, the hierarchical structure and index relationship of the algorithm system in this study have not been verified by simulation. Therefore, further practice is needed in future research to increase the application value of the model.

\section{Data Availability}

The data used to support the findings of this study are available from the corresponding author upon request.

\section{Conflicts of Interest}

The authors declare that they have no conflicts of interest.

\section{References}

[1] M. Bremmer and L. Nijs, "The role of the body in instrumental and vocal music pedagogy: a dynamical systems theory perspective on the music teacher's bodily engagement in teaching and learning," Frontiers in Education, vol. 5, p. 79, 2020.

[2] J. I. Lu, "Exploration of the use and reform of vocal music teaching materials in Chinese art colleges," Canadian Social Science, vol. 10, no. 5, pp. 35-37, 2014. 
[3] W. E. I. Yan, "Thought on construction of vocal music curriculum group in normal universities," Higher Education of Social Science, vol. 8, no. 3, pp. 132-135, 2015.

[4] B. E. Nichols, "Effect of vocal versus piano doubling on children's singing accuracy," Psychology of Music, vol. 49, no. 5, pp. 1415-1423, 2021.

[5] B. F. Yue, "The application of multimedia technology in vocal music teaching," Advanced Materials Research, vol. 926-930, pp. 754-758, 2014.

[6] L. Morrow Sharon and P. Connor Nadine, "Comparison of voice-use profiles between elementary classroom and music teachers," Journal of Voice: Official Journal of the Voice Foundation, vol. 25, no. 3, pp. 49-52, 2010.

[7] Y. Yang, "Application of multimedia technology in vocal music digital teaching reform," Journal of Physics: Conference Series, vol. 1648, no. 4, Article ID 042005, 2020.

[8] Shono, M. Yoshida, M. Ogawa et al., "A questionnaire investigation on prevalence of subjective hoarseness among public school teachers undergoing complete in-hospital physical examination," Japan Journal of Logopedics and Phoniatrics, vol. 50, no. 4, pp. 687-690, 2010.

[9] Y. Liu, Z. Sun, and J. H. Chen, “A film criticism website based on "ThinkPHP”," International Journal of Advanced Pervasive and Ubiquitous Computing, vol. 9, no. 1, pp. 149-152, 2017.

[10] Qiu and Q. Y. Zhu, "A case study for high-level course website based on muti-technology integration," Applied Mechanics and Materials, vol. 263-266, pp. 419-421, 2013.

[11] Qiu, L. Zhou, and Q. Y. Zhu, "A case study for high-level course website development based on RFID and face recognition[J]," Applied Mechanics and Materials, vol. 411-414, pp. 45-50, 2013.

[12] G. Y. Han and X. Z. Li, "The implementation of rights management of network teaching platform with role-based access control," Applied Mechanics and Materials, vol. 433435, pp. 53-58, 2013.

[13] T. Varrecchia, C. De Marchis, M. Rinaldi et al., "Lifting activity assessment using surface electromyographic features and neural networks," International Journal of Industrial Ergonomics, vol. 66, pp. 1-9, 2018.

[14] J. S. Paiva, J. Cardoso, and T. Pereira, "Supervised learning methods for pathological arterial pulse wave differentiation: a SVM and neural networks approach," International Journal of Medical Informatics, vol. 109, pp. 30-38, 2018.

[15] Nguyen, V. Bui, and N. George, "Computational optical tomography using 3D deep convolutional neural networks (3D-DCNNs)," Optical Engineering, vol. 57, no. 4, 2018.

[16] Y.-C. Wang, M.-T. Li, Z.-C. Pan, and J.-H. Zheng, "Pulsar candidate classification with deep convolutional neural networks," Research in Astronomy and Astrophysics, vol. 19, no. 9, p. 133, 2019.

[17] B. Sinchev, S. E. Sibanbayeva, A. M. Mukhanova et al., "Some methods of training radial basis neural networks in solving the Navier-Stokes equations," International Journal for Numerical Methods in Fluids, vol. 86, no. 10, pp. 625-636, 2018. 